OPEN ACCESS

Edited by:

Tamás Laskay,

University of Lübeck, Germany

Reviewed by:

Dane Parker

The State University of New Jersey,

United States

Patricia Talamás-Rohana, National Polytechnic Institute of

Mexico (CINVESTAV), Mexico

${ }^{*}$ Correspondence:

Fangli Lu

fanglilu@yahoo.com

Specialty section

This article was submitted to

Microbial Immunology,

a section of the journal

Frontiers in Immunology

Received: 20 March 2020

Accepted: 06 July 2020

Published: 26 October 2020

Citation:

Ma Y, Su X-z and Lu F (2020) The

Roles of Type I Interferon in

Co-infections With Parasites and

Viruses, Bacteria, or Other Parasites.

Front. Immunol. 11:1805.

doi: 10.3389/fimmu.2020.01805

\section{The Roles of Type I Interferon in Co-infections With Parasites and Viruses, Bacteria, or Other Parasites}

\author{
Yuanlin $\mathrm{Ma}^{1}$, Xin-zhuan $\mathrm{Su}^{2}$ and Fangli $\mathrm{Lu}^{3,4 *}$ \\ ${ }^{1}$ Zhongshan School of Medicine, Sun Yat-sen University, Guangzhou, China, ${ }^{2}$ Laboratory of Malaria and Vector Research, \\ National Institute of Allergy and Infectious Disease, National Institutes of Health, Bethesda, MD, United States, ${ }^{3}$ Department \\ of Parasitology, Zhongshan School of Medicine, Guangzhou, China, ${ }^{4}$ Key Laboratory of Tropical Disease Control of Ministry \\ of Education, Sun Yat-sen University, Guangzhou, China
}

Parasites, bacteria, and viruses pose serious threats to public health. Many parasite infections, including infections of protozoa and helminths, can inhibit inflammatory responses and impact disease outcomes caused by viral, bacterial, or other parasitic infections. Type I interferon (IFN-I) has been recognized as an essential immune effector in the host defense against various pathogens. In addition, IFN-I responses induced by co-infections with different pathogens may vary according to the host genetic background, immune status, and pathogen burden. However, there is only limited information on the roles of IFN-I in co-infections with parasites and viruses, bacteria, or other parasites. This review summarizes some recent findings on the roles of IFN-I in co-infections with parasites, including Leishmania spp., Plasmodium spp., Eimeria maxima, Heligmosomoides polygyrus, Brugia malayi, or Schistosoma mansoni, and viruses or bacteria and co-infections with different parasites (such as co-infection with Neospora caninum and Toxoplasma gondii, and co-infection with Plasmodium spp. and $H$. polygyrus). The potential mechanisms of host responses associated with co-infections, which may provide targets for immune intervention and therapies of the co-infections, are also discussed.

Keywords: type I interferon, parasite, virus, bactirum, co-infection

\section{INTRODUCTION}

Interferons (IFNs) were initially discovered as soluble effector molecules influencing viral replication in 1957 (1). There are three types of IFNs, including type I interferon (IFN-I), type II interferon (IFN-II), and type III interferon (IFN-III). There are 20 subtypes of IFN-I, including 14 subtypes of IFN $\alpha$, IFN $\beta$, IFN $\varepsilon$, IFNא, IFN $\tau$, IFN $\delta$, and IFN $\zeta$, with IFN $\alpha$ and IFN $\beta$ being expressed at the highest levels generally (2). Some researchers suggested that IFN-I should contain IFN $\omega$, because IFN $\omega$ shares $62 \%$ and $33 \%$ amino acid sequence homology with IFN $\alpha$ and IFN $\beta$, respectively (3). All the IFN-I subtypes exert biological activity through common receptors, IFN $\alpha / \beta$ receptor (IFNAR1 and IFNAR2). IFN-II contains only one subtype, IFN $\gamma$, which exerts its biological activity through IFN $\gamma$ receptor (IFNGR). IFN-III includes four subtypes of IFN $\lambda$, e.g., IFN $\lambda 1$ or named interleukin (IL)-29, IFN $\lambda 2$ or named IL-28A, IFN $\lambda 3$ or named IL-28B, and IFN $\lambda 4$ (4). All the IFN-III subtypes have similar functions to those of IFN-I in antiviral infections and mucosal immunity through IFN $\lambda$ receptor (IFNLR) (5). 
IFN-I binds to IFNARs and activates Janus kinase 1 (JAK1) and tyrosine kinase 2 (TYK2), leading to phosphorylation and subsequent heterodimerization of signal transducers and activators of transcription 1 (STAT1) and STAT2 that bind to IFN regulatory factor 9 (IRF9) to form a complex named IFNstimulated gene factor 3 (ISGF3) (6). ISGF3 translocates into the nucleus and binds to the IFN-stimulated response element that resides within the promotor region of IFN-stimulated genes (ISGs) (7). It was previously thought that IFN-I and IFN-III had important roles for antiviral infections and mucosal immunity, and IFN-II were mainly involved in antiparasitic infections (5). However, it has been found that IFN-I is also indispensable in anti-parasitic infections (8). In this review, we summarized current understanding on the roles of IFN-I in co-infections with parasites and viruses, bacteria, or other parasites through the searching of PubMed. Our results show that a host's immune response to infection with different parasites can influence susceptibility to infection of other pathogens, and IFN-I play critical roles in host response to co-infections. Elucidation of the molecular mechanisms of IFN-I responses in co-infections will be essential for developing effective therapies for infectious diseases caused by the pathogens.

\section{THE ROLE OF IFN-I IN CO-INFECTIONS WITH PROTOZOA AND VIRUSES}

\section{The Roles of IFN-I in Co-infections With Leishmania Spp. and Viruses}

Leishmania braziliensis and Leishmania guyanensis often carry a single-segmented double-stranded RNA (dsRNA) Totivirus known as Leishmania RNA virus 1 (LRV1) (9). In human, LRV1 multiplying within L. guyanensis and L. braziliensis parasites can cause more severe diseases, more frequent relapse after drug treatment, or increased risk of treatment failure than infections with the parasites alone $(10,11)$. Co-infection with the lymphocytic choriomeningitis virus (LCMV) or Toscana virus can exacerbate the outcome of L. guyanensis-induced murine leishmaniasis and benefit parasite persistence and dissemination (11). Furthermore, LCMV co-infection after healing of leishmaniasis may induce reactivation of disease pathology, overriding the protective adaptive immune response.

\footnotetext{
Abbreviations: ALT, alanine transaminase; AST, spartate transaminase; cGAMP, cyclic GMP-AMP; cGAS, cyclic GMP-AMP synthase; DC, dendritic cell; gDNA, genomic DNA; $\mathrm{G}^{-}$, Gram-negative; $\mathrm{G}^{+}$, Gram-positive; $\mathrm{HCV}$, hepatitis $\mathrm{C}$ virus; HIV, human immunodeficiency virus; HSV, herpes simplex virus; IFN, interferon; IFNAR, IFN $\alpha / \beta$ receptor; IFNAR $^{-/-}$, type I IFN receptor deficient; IFNGR, IFN $\gamma$ receptor; IFN-I, type I interferon; IFN-II, type II interferon; IFN-III, type III interferon; IFNLR, IFN $\lambda$ receptor; IL, interleukin; IRF, IFN regulatory factor; ISGF3, IFN-stimulated gene factor 3; ISGs, IFN-stimulated genes; JAK1, Janus kinase 1; LCMV, lymphocytic choriomeningitis virus; LDV, lactate dehydrogenase-elevating virus; LRV1, Leishmania RNA virus 1; NO, nitric oxide; oas, 2'-5'-Oligoadenylate synthetase; pDC, plasmacytoid dendritic cell; PEG-IFN $\alpha$, Pegylated-IFN $\alpha-2 \mathrm{a}$; $p k r$, protein kinase R; PRR, pathogen recognition receptor; PVM, pneumovirus of mice; ROP16, rhoptry protein 16; RSV, respiratory syncytial virus; STAT, signal transducers and activators of transcription; STING, stimulator of IFN genes; TLR, toll-like receptor; TNF $\alpha$, tumor necrosis factor $\alpha$; TRIF, TIR-domain-containing adaptor-inducing IFN $\beta$; TYK2, tyrosine kinase 2; WT, wild-type.
}

Mice infected with LRV1-bearing L. guyanensis have larger lesions and increased parasite load, and induce a significant down-regulation of IFNGR expression than mice infected with LRV1-cured L. guyanensis (11). IFN $\alpha$ and IFN $\beta$ have a dose-dependent effect on increasing the lesion size and parasite number in C57BL/6 wild-type (WT) mice infected with L. guyanensis. In contrast, IFN-I receptor deficient $\left(\right.$ IFNAR $^{-/-}$) mice infected with LRV1-bearing L. guyanensis have significantly smaller lesions and decreased parasite numbers, similar to those observed in IFNAR $^{-/-}$and WT mice infected with LRV1cured L. guyanensis (11). Another study tested the effects of co-infection with two Phlebovirus isolates, Icoaraci and Pacui from the Amazon region. Increased inflammatory infiltrates with higher IFN $\beta$-expressing cell numbers and parasite burden, and larger lesion size were observed in Phlebovirus IcoaraciLeishmania amazonensis co-infected mice than those singly infected with L. amazonensis. These observations were partially corroborated with Phlebovirus Pacui co-infection. Phlebovirus Icoaraci aggravates in vivo L. amazonensis infection via the engagement of the RNA sensor protein kinase R (PKR) and the expression of IFN $\beta$ and IL-10. Furthermore, co-infection with Phlebovirus potentiates in vitro L. amazonensis infection, and increased macrophage infection requires IFN $\beta$ expression induced by the parasite and amplified during co-infection (12). However, dengue virus type-2 co-infection can negatively modulate the intracellular growth of L. amazonensis and prevent the expression of IFN $\beta$ and IL-10 in macrophages when compared to macrophages infected with L. amazonensis only (12). Dengue virus type-2 might impair IFN-I signaling cascade in vertebrate cells leading to defective $\operatorname{IFN}$ expression $(13,14)$. Therefore, viral co-infection can modulate host responses to Leishmania infections leading to different disease outcomes, depending on the virus species.

\section{The Roles of IFN-I in Co-infections With Plasmodium Spp. and Viruses}

An estimated 228 million cases of malaria occurred worldwide and 405,000 deaths from malaria globally in 2018 (15). It has been reported that Plasmodium and respiratory syncytial virus infections remain common among children in subSaharan Africa, and that febrile young children concurrently infected with Plasmodium and respiratory viral pathogens are less likely to suffer from pneumonia than non-Plasmodiuminfected children (16). After C57BL/6J mice were simultaneously infected with pneumovirus of mice (PVM) and blood-stage of Plasmodium chabaudi chabaudi AS parasites, P. chabaudi chabaudi AS infection was unaffected by co-infection with PVM, while PVM-induced weight loss, diminished pulmonary cytokine responses and immune cell recruitment to the airways, and greater viral dissemination throughout the lung were observed by co-infection with $P$. chabaudi chabaudi AS. As a result, Plasmodium co-infection induced immunosuppression in the lung is associated with disruption of early systemic IFN $\beta$ response to PVM, leading to exacerbating viral dissemination in the lung, which does not occur during infection with PVM alone (17). These data provide evidence that co-infection 
with P. chabaudi chabaudi AS and PVM drives a unique IFN $\beta$ response that does not occur during infection with PVM alone. In $\mathrm{C} 57 \mathrm{BL} / 6$ mice, it was found that both live blood cells and extracts of blood cells parasitized by Plasmodium berghei K173 or Plasmodium yoelii 17X YM can protect against $P$. berghei ANKAinduced experimental cerebral malaria (ECM) (18). P. berghei K173 triggered an early production of IFN $\alpha$, CCL4, CCL5, tumor necrosis factor alpha (TNF $\alpha)$, IL-6, and IL-12p40, and the protection was associated with a strong IFN-I signature (18). P. berghei K173 and P. yoelii 17X YM contain lactate dehydrogenase-elevating virus (LDV), a nonpathogenic mouse virus, which alone protects mice from ECM (18). In ECM, LDV induces a massive IFN-I response, resulting in an IFN-mediated reduction in the number of splenic conventional dendritic cells (cDCs) and an impairment of their ability to produce IL-12p70, leading to a decrease in pathogenic Th1 $\mathrm{CD} 4^{+} \mathrm{T}$ cell responses. $P$. berghei ANKA induced upregulation of the IL-12p35 and IL12 p40 genes, which was blocked by LDV co-infection but rescued in IFNAR $1^{-/-}$mice. IFN $\alpha$, IFN $\beta$, TNF $\alpha$, and IL- 6 genes were induced, and splenic T cells and DCs were activated in ECM, which were also reversed in IFNAR $1^{-/}$mice (18). Thus, IFNI are powerful signals that can modify the functionality of many cell types and contribute to the control of Plasmodium spp. and viruses co-infection.

\section{The Roles of IFN-I in Co-infections With Toxoplasma gondii and Viruses}

T. gondii is an obligate intracellular parasite that has a wide intermediate host range including humans (19). Immunocompromised patients infected with HIV are likely to suffer from T. gondii infection. To examine how HIV-infected cells were recognized by plasmacytoid dendritic cells (pDCs) and other cells, Lepelley et al. (20) used inhibitors to silence toll-like receptor 7 (TLR7) signaling and found that recognition of virus molecules occurred in primary pDCs and pDC-like cells through TLR7. TTAGGG motifs containing inhibitory oligodeoxynucleotide efficiently block the TLR9 signaling and herpes simplex virus (HSV)-induced IFN-I production by pDCs (21). After recognition, an intracellular signaling pathway is activated in pDCs, including endosomal localization of TLR9 leading to phosphorylation and nuclear translocation of IRF7. The transcription factor IRF7 is essential for the induction of IFN $\alpha / \beta$ genes via the virus-activated, MyD88-independent pathway, and the TLR-activated, MyD88-dependent pathway (22). T. gondii infected human pDCs could functionally inhibit pDCs from producing IFN $\alpha$ responding to HIV-1 or HSV-1 during co-infection (23). The inhibition of IFN $\alpha$ production in response to HSV-1 infection has a dose-dependent effect on the ratio of $T$. gondii to human peripheral blood mononuclear cell counts, whereas uninfected cells responded normally to HSV-1 stimulation. Similar results were found for IFN $\alpha$ production in response to T. gondii-HIV co-infections. T. gondii rhoptry protein 16 (ROP16) is responsible for inhibition of IRF7 nuclear translocation and inhibition of IFN $\alpha$ production (23). ROP16 knockout RH strain of T. gondii failed to inhibit IRF7 nuclear translocation as compared to the WT RH strain. pDCs from mice infected with ROP16 knockout T. gondii produced more IFN $\alpha$ than those infected with WT parasites, indicating that ROP16mediated phosphorylation of STAT3 is an important mechanism for T. gondii inhibition of IFN $\alpha$ production. IL-10 also inhibits IRF7 nuclear translocation in pDCs after stimulation with HSV-1, which is one of the important mechanisms for T. gondii inhibition of IFN $\alpha$ production. T. gondii suppresses $\mathrm{pDC}$ activation by mimicking IL-10's regulatory effects through an ROP16 kinase-dependent mechanism (23). These data provide evidence of inhibition of innate immune responses to HIV-1 and HSV-1 by T. gondii through inhibition of IFN $\alpha$ production.

\section{THE ROLES OF IFN-I IN CO-INFECTIONS WITH HELMINTHS AND VIRUSES}

\section{The Roles of IFN-I in Co-infection With Heligmosomoides polygyrus and Virus}

Mice co-infected with the gastrointestinal helminths Trichinella spiralis or $H$. polygyrus and mouse norovirus showed increased viral loads and reduced levels of virus-specific $\mathrm{CD}^{+} \mathrm{T}$ cells expressing IFN $\gamma$ and $\mathrm{TNF} \alpha$ than mice infected with norovirus alone, indicating helminth infection suppresses antiviral immunity (24). However, $H$. polygyrus infection can also induce protective immunity against viral infections. McFarlane et al. (25) infected mice with 2003 rd stage larvae of $H$. polygyrus by oral gavage and then infected the mice with respiratory syncytial virus (RSV) or UV-inactivated RSV by intranasal dropping 10 days later. It was found that enteric $H$. polygyru infection upregulated expressions of IFN-I and ISGs in both the duodenum and the lung, resulting in the reduction of RSV load as well as pulmonary inflammation. In germ-free IFNAR $1^{-/-}$mice, the protection (e.g., reduction of RSV load and the induction of ISG) was lost, indicating $H$. polygyrus-induced protection against RSV infection requires IFNAR signaling. $H$. polygyrus adult excretory and secretory products are not responsible for the effects of RSV infection, while larval stages alone are required to protect against RSV infection (25). Two ISGs, oas and viperin, have been found to be driven by IFN-I and play a protective role in RSV infection $(26,27)$. These data demonstrate that enteric helminth infection can have protective antiviral effects in the lung through induction of RSV-dependent IFNI response.

\section{The Roles of IFN-I in Co-infection With Schistosoma mansoni and Viruses}

Schistosoma spp. are responsible for human schistosomiasis. C57BL/6 mice were percutaneously infected with 25 or $50 \mathrm{~S}$. mansoni cercariae, and then were intravenously inoculated with $10^{5} \mathrm{PFU}$ of a hepatotropic strain of LCMV (WE2.2) 10 weeks later. Schistosome egg antigens were shown to suppress IFN-I response by DCs and enhance intrahepatic LCMV replication in the co-infected mice (28). On the other hand, the co-infected mice showed a significantly higher hepatic egg burden, leading to a dramatic increase in morbidity and mortality associated with the increased serum levels of aspartate transaminase 
(AST), alanine transaminase (ALT), and nitric oxide (NO). Compared to mice infected with schistosome or LCMV alone, the high serum AST and ALT levels in the co-infected mice indicate a substantial degree of liver damage, likely due to increased serum NO production in the co-infected mice (28). The results are similar to the observations in a study of 126 Egyptian patients, in which patients co-infected with hepatitis C virus (HCV) and S. mansoni have more advanced liver disease, with higher HCV RNA titers, higher hepatic inflammatory and fibrosis/cirrhosis scores, higher incidence of hepatocellular carcinoma, and higher mortality rate than patients with $\mathrm{HCV}$ infection alone (29). Furthermore, HCV and S. mansoni coinfection had either no or weak $\mathrm{CD} 4^{+} \mathrm{T}$ cell response compared to patients with HCV infection alone (30). Therefore, coinfection of viruses can affect the parasite infection, and vice versa. Pegylated-IFN $\alpha-2$ a (PEG-IFN $\alpha$ ) is a standard treatment for HCV infection and can reduce granuloma size and adult parasite counts in S. mansoni-mono-infected albino mice. PEGIFN $\alpha$ treatment results in significantly (35\%) lower total worm burdens and up to $80 \%$ lower egg count in the livers. Interferon treatment also increases the proportion of single worms over parasites in pairs (31). However, a retrospective analysis of 3,596 chronic HCV patients in Egypt, who received PEGIFN $\alpha$ after antischistosomal therapy for schistosomiasis, showed that positive schistosomal serology has no effect on fibrosis staging but is significantly associated with failure of response to HCV treatment despite antischistosomal therapy (32). Because schistosomiasis is significantly associated with failure to respond to HCV treatment, Schistosoma infections diagnosed by serology should be considered for chronic HCV patients prior to initiating PEG-IFN $\alpha$ therapy.

\section{THE ROLES OF IFN-I IN CO-INFECTIONS OF PROTOZOA WITH BACTERIA}

\section{The Roles of IFN-I in Co-infection With Eimeria maxima and Bacteria}

Clostridium perfringens is a Gram-positive $\left(\mathrm{G}^{+}\right)$pathogenic bacterium and the causative agent of necrotic enteritis (33). Co-infection with C. perfringens and E. maxima, a protozoan parasite living in the gut and causing coccidiosis in poultry, has been strongly implicated in promoting necrotic enteritis (34). In one study, 3-week-old chickens were orally infected with $5 \times 10^{4}$ sporulated oocysts of E. maxima, and then orally infected with $10^{9} \mathrm{C}$. perfringens bacteria 5 days later. The results showed a synergistic relationship during the course of experimental necrotic enteritis. E. maxima/C. perfringens coinfection resulted in more severe intestinal pathology, reduced body weight gain, increased numbers of intestinal $C$. perfringens bacteria, and altered cytokine/chemokine expression compared to chickens exposed to E. maxima or C. perfringens alone (35). Co-infection of E. maxima with $C$. perfringens suppressed the expression of IFN $\alpha$, IFN $\gamma$, IL-1 $\beta$, IL-2, IL-12, IL-13, IL-17, NO, and transforming growth factor- $\beta 4$ genes, but increased the expression of IL-8, IL-10, IL-15, and lipopolysaccharide-induced $\mathrm{TNF} \alpha$ factor (35). Therefore, IFN $\alpha$ is considered to have a role in disease severity upon co-infection of E. maxima with C. perfringens.

\section{The Roles of IFN-I in Co-infection With $P$. falciparum and Bacteria}

Co-infections with bacteria and malaria parasites are common life-threatening conditions in children residing in sub-Saharan Africa (36). It has been reported that the most frequently isolated $\mathrm{G}^{+}$and Gram-negative $\left(\mathrm{G}^{-}\right)$bacteria found from 206 children aged 3-36 months in Kenya are Staphylococcus aureus $\left(\mathrm{G}^{+}\right.$bacteria) and non-Typhi Salmonella ( $\mathrm{G}^{-}$bacteria), respectively (36). Kenyan children co-infected with $\mathrm{G}^{-}$bacteria and $P$. falciparum can increase clinical outcomes such as malnutrition, respiratory distress, anemia, and mortality, although bacteremia is associated with reducing incidences of high-density parasitemia (37). Severe anemia in malaria patients is not affected by co-infection with $\mathrm{G}^{-}$bacteria, and $P$. falciparum burden in $\mathrm{G}^{-}$bacteria co-infected patients has five-fold lower median parasitemia and six-fold lower geometric mean parasitemia than those of $P$. falciparum-mono-infected patients. In addition, cytokines including IL-4, IL-5, IL-7, IL-12, IL-15, IL-17, IFN $\alpha$, and IFN $\gamma$ are higher in patients co-infected with P. falciparum and $\mathrm{G}^{-}$or $\mathrm{G}^{+}$bacteria than P. falciparum mono-infected patients. Parasitemia is inversely associated with elevated levels of IL-1 $\beta$, IL-1Ra, IL-12, IL-15, IL-17, IFN $\alpha$, and IFN $\gamma$ in children co-infected with $P$. falciparum and $\mathrm{G}^{-}$bacteria, suggesting that the cytokines may induce anti-parasitic activities (36). Furthermore, children with P. falciparum-mono-infection had significantly depressed levels of IFN $\alpha$ compared to children with $\mathrm{G}^{-}$or $\mathrm{G}^{+}$bacteria and P. falciparum co-infections (36). These data suggest that enhanced immune activation, especially increased serum level of IFN $\gamma$ and IFN $\alpha$ in co-infected children, may act to reduce malaria parasite densities in these individuals.

\section{THE ROLES OF IFN-I IN CO-INFECTIONS WITH HELMINTH AND BACTERIA}

\section{The Roles of IFN-I in Co-infection With Brugia malayi and Bacteria}

Brugia malayi is a parasitic nematode and etiological agent of lymphatic filariasis. Human DCs infected with Mycobacterium tuberculosis produce IL-1 $\beta$, IL-12, IL-18, IFN $\alpha$, and TNF $\alpha$ to activate $\mathrm{T}$ cells and trigger adaptive immunity (38). Similarly, human macrophages infected with $M$. tuberculosis produce IL$1 \beta$, IL-6, IL-10, IL-18, and TNF $\alpha$ (38). Activated macrophages can kill $M$. tuberculosis in the presence of IFN $\gamma$ produced by activated $\mathrm{T}$ cells (39). In one study, human DCs and macrophages were exposed in vitro to 12,500 live B. malayi microfilariae on day 7 and then were infected with $M$. tuberculosis strain $\mathrm{H} 37 \mathrm{Rv}$ on day 9. It was found that pre-exposure of $B$. malayi microfilariae decreased the expression of IL-10, IFN $\alpha$, and macrophage inflammatory protein-1 $\beta$ by DCs and the expression of IL-10 and IFN $\alpha$ by macrophages after infection with $M$. tuberculosis (40). IL-10 and IFN $\alpha$ are important for treating tuberculosis, and the decreased expression of IL-10 and IFN $\alpha$ can lead to a significant impairment of antimicrobial 
activity (41). When cultured with autologous $\mathrm{CD} 4^{+} \mathrm{T}$ cells, live microfilariae-exposed and M. tuberculosis-infected DCs were less capable of stimulating IFN $\gamma$ production, leading to a significant impairment in limiting mycobacterial growth (40). These data demonstrate that filarial parasites can affect the functions of DCs and macrophages and have an impact on the outcome of concurrent $M$. tuberculosis infection.

\section{THE ROLE OF IFN-I IN CO-INFECTION WITH DIFFERENT PROTOZOA \\ The Roles of IFN-I in Co-infection With Neospora caninum and T. gondii}

$N$. caninum is an intracellular protozoan that infects many animals, and is similar to $T$. gondii in morphology and developmental stages, but there are differences in many genes between these two parasites (42). In an in vitro study, after pre-infection with $N$. caninum, human fibroblasts can induce a strong IFN-I response to control T. gondii infection, but not vice versa. In contrast, pre-infection with $T$. gondii for $1 \mathrm{~h}$ followed by heat-killed $N$. caninum failed to induce human fibroblasts to produce IFN-I (43). Therefore, IFN-I induced by atypical strains of T. gondii and/or N. caninum can cause suppression of IFN $\gamma$ production and more severe disease (8). The results demonstrate that $N$. caninum is a potent inducer of innate IFN $\alpha / \beta$ responses, and that $T$. gondii has the capacity to suppress the responses.

\section{The Roles of IFN-I in Co-infection With Protozoa and Helminth}

To investigate whether Plasmodium infections compromise antihelminth immunity, Coomes et al. (44) infected C57BL/6 mice with 2003 rd stage larvae of $H$. polygyrus by oral gavage and then intraperitoneally injected $10^{5} \mathrm{P}$. chabaudi chabaudi AS parasitized red blood cells into the mice 6 days later. Reduced anti-helminth Th2 cell responses and compromised anti-helminth immunity were found during $H$. polygyrus and $P$. chabaudi co-infections, which protected recipient mice from high parasitemia of malaria parasites. Both IFN-I responsive and unresponsive Th2 cells can up-regulate IFN $\gamma$ and increase serum IFN $\gamma$ levels, providing protection against high parasitemia similarly observed in either IFNAR ${ }^{-/-}$or IFNAR ${ }^{+/+}$mice (44). However, in another study, IFN-I was shown to be essential for IFN $\gamma$ production from converted Th2 cells (45). The study indicates that Plasmodium infection can negatively affect antihelminth responses by reducing Th2 cell reaction.

\section{MOLECULAR SIGNALING FOR IFN-I RESPONSE TO CO-INFECTIONS}

\section{IFN-I Response to Co-infection With Parasites and Viruses}

Recognition of pathogen-associated molecular patterns by pathogen recognition receptors (PRRs) such as TLRs leads to production of IFN-I. TLRs are some of the most important PRRs, and pDCs are one of the major cells producing IFNI (23). In P. chabaudi chabaudi AS and PVM co-infected mice, activation of pDCs was boosted via several PRRs such as TLR7 in $\mathrm{pDC}$ recognition of PVM, and TLR9 and stimulator of IFN genes (STING) through recognition of AT-rich DNA bound to Plasmodium-derived hemozoin (46-48). In P. berghei ANKA and LDV co-infected mice, LDV nucleic acid was recognized by TLR7 and induced a rapid systemic IFN-I production by pDC (49). IFN-I signaling crippled cDC quantitatively and qualitatively, leading to a decrease of IL-23 production that is responsible for the pathogenic polarization of $\mathrm{CD}^{+} \mathrm{T}$ cells in $P$. berghei ANKA-induced ECM (18). Genes known to be stimulated by IFN-I, including those encoding $2^{\prime}-5^{\prime}$-oligoadenylate synthetase (oas1a), oas2, oasl2, or $p k r$, are significantly up-regulated in mice co-infected with LRV1-bearing L. guyanensis or LRV1cured L. guyanensis and LCMV, compared to mice infected with LRV1-cured L. guyanensis alone (11). The dsRNA of LRV1 acts to promote L. guyanensis virulence through TLR3 and IFNI signaling $(11,50)$. L. guyanensis parasites with a high LRV1 burden promote TLR3-dependent secretion of proinflammatory cytokines, chemokines, and IFN $\beta$ (51). Although miRNA-155 is the only microRNA up-regulated in macrophages in the presence of LRV1 in a TLR-3/TIR-domain-containing adaptorinducing IFN $\beta$ (TRIF)-dependent manner, the secretion of proinflammatory cytokines (TNF $\alpha, \mathrm{IL}-6$, and IFN $\beta$ ) and the mRNA expression of IFN $\beta$ or the phosphorylation of IRF- 3 of primary murine macrophages are not dependent on miRNA-155 in response to poly I:C or co-infection with $L$. guyanensis and LRV1 (50). Phlebovirus Icoaraci reduced PKR phosphorylation that induced by L. amazonensis at 1 and $4 \mathrm{~h}$ post infection. Furthermore, Phlebovirus Icoaraci induced and sustained PKR activation, leading to enhanced IL-10 expression, suggesting a synergism between L. amazonensis and Phlebovirus Icoaraci (12). The innate IFN $\alpha$ response induced via TLR7/9 by HIV-1 or HSV1 in human pDCs is suppressed by ROP16 kinase of T. gondii through IL-10 mediated inhibition of HSV-induced IRF7 nuclear translocation (23). In $H$. polygyrus and RSV co-infected mice, $H$. polygyrus infection induces up-regulation of IFN $\beta$ transcription and IFN $\alpha$ protein levels in the lung at very early time points after infection. Using IFNAR $1^{-/-}$mice, enteric helminth infection has protective antiviral effects in the lung through induction of a microbiota-dependent IFN-I response, which is critical to antiRSV immunity (25). Alveolar macrophages are the major source of IFN-I upon RSV infection in mice (52), and rapid and strong IFN-I and ISG responses can be induced upon stimulation of a virus such as RSV (53). Schistosome eggs contained dsRNA that is able to trigger DC activation via TLR3 (54). Schistosome eggs induce IFN $\beta$ expression and trigger IFNAR expressed on DCs, resulting in phosphorylation of STAT1 and up-regulation of IFNinduced inflammatory products (55). However, in S. mansoni and LCMV co-infected mice, schistosome egg antigens suppress IFN-I response in DCs induced by LCMV (28).

\section{IFN-I Response to Co-infection With Parasites and Bacteria}

Malarial parasite DNA bound to hemozoin pigment is targeted to intracellular compartments to activate TLR9 (56), and TLR9 and $\mathrm{MyD} 88$ play central roles in the immune regulation and development of protective immunity to malaria (57). DNA from the parasites can be recognized by cytosolic sensors such as cyclic 
GMP-AMP synthase (cGAS) through STING, TBK1, and IRF3IRF7 pathway to induce IFN-I that can recruit natural killer $\mathrm{T}$ cells to produce IFN $\gamma(8,48,58)$. Mice deficient in cGAS, STING, MDA5, MAVS, or IRF3 produced high amounts of IFN $-\alpha / \beta$ in the serum and are resistant to lethal $P$. yoelii $\mathrm{YM}$ infection, suggesting that activation of cGAS-STING and MDA5-MAVS-mediated IRF3-dependent IFN-I signaling leads to a lethal P. yoelii YM infection (58). Furthermore, pDCs, cDCs, and macrophages are required for generating IFN- $\alpha / \beta$-induced subsequent protective immunity and suppressor of cytokine signaling 1 works as a key negative regulator to inhibit MyD88-dependent IFNI signaling in pDCs. These data identify a critical regulatory mechanism between different IFN-I signaling pathways in pDCs as well as a critical role of stage-dependent IFN-I production in developing protective immunity (58). IFN-I were induced in human primary $\mathrm{CD} 14^{+}$monocytes purified from peripheral blood mononuclear cells in response to $P$. falsiparum genomic DNA (59). In addition, IFN $\alpha$ and IFN $\gamma$ are significantly increased in patients co-infected with P.falciparum and $\mathrm{G}^{-}$or $\mathrm{G}^{+}$ bacteria compared to $P$. falciparum mono-infected patients. IFN $\alpha$ plays an important role in parasite clearance possibly via induction of NO, which is associated with reduced parasitemia (60). Further studies are needed to understand the molecular mechanisms responsible for the role of IFN-I in malaria and bacterial infection.

In co-infection with $B$. malayi and $M$. tuberculosis, the decreased function of DCs and macrophages to migrate and present antigens to $\mathrm{T}$ cells results in decreased expression of cytokines such as IL-10, IFN $\alpha$, and IFN $\gamma$ (40). In E. maxima and $C$. perfringens co-infected chickens, the expressions of IFN $\alpha$, IFN $\gamma$, and NO are repressed, while IL-10 expression is upregulated (35). IL-10 inhibits IFN $\gamma$ expression and prevents the development of IFN $\gamma$-driven responses, which is crucial for control of E. maxima infection (61). Clostridium orbiscindens produced desaminotyrosine that primes the amplification loop of IFN-I signaling to protect the host (62). However, whether C. perfringens can also produce desaminotyrosine needs to be further studied.

\section{IFN-I Response to Co-infection With Different Parasites}

In T. gondii and N. caninum co-infected mice, N. caninum RNA can induce IFN-I responses to N. caninum or heat-killed T. gondii via TLR3 and TRIF, suggesting that parasite RNA is a potential trigger for this response (43). TLR3-dependent induction of

\section{REFERENCES}

1. Isaacs A, Lindenmann J. Virus interference. I The interferon. Proc $R$ Soc Lond B Biol Sci. (1957) 147:258-67. doi: 10.1098/rspb.1957. 0048

2. Ahmed D, Cassol E. Role of cellular metabolism in regulating type I interferon responses: Implications for tumour immunology and treatment. Cancer Lett. (2017) 409:20-9. doi: 10.1016/j.canlet.2017. 08.037
IFN-I responsive genes can be elicited by the transfection of macrophages with $N$. caninum RNA, but not with T. gondii RNA (43). Profilin of T. gondii is the ligand for TLR11 and TLR12 and boosts host immune responses through the activation of IL-12 and IFN $\alpha$ in mice $(63,64)$.

\section{CONCLUDING REMARKS}

Co-infections with parasites and viruses, bacteria, or other parasites are quite common in patients. Increasing evidences show that co-infections with these infectious agents may alter host immune responsiveness and disease outcomes. IFN-I plays important roles during the co-infections, which can either deteriorate or attenuate the consequence of diseases via the interactions. However, so far the literatures about IFN-I in coinfections with parasites and viruses, bactera, or other parasites are limited. A better understanding of how the susceptibility and pathogenesis of infectious disease can be influenced by parasite co-infections, and the mechanisms of IFN-I response in coinfection may yield new therapies for more effective control of the infectious diseases.

\section{AUTHOR CONTRIBUTIONS}

YM wrote the manuscript draft. X-zS revised and edited the manuscript. FL conceived and wrote the manuscript. All authors contributed to the article and approved the submitted version.

\section{FUNDING}

This work was supported by the Natural Science Foundation of China (Nos. 81971955 and 81471973), the Natural Science Foundation of Guangdong Province, China (No. 2019A1515011667), the Intramural Research Program of the National Institute of Allergy and Infectious Diseases, National Institutes of Health (X-zS), the open project of Key Laboratory of Tropical Disease Control of Ministry of Education, Sun Yat-sen University, China (No. 2020ZX02), and the undergraduate teaching quality engineering and teaching reform project of Sun Yat-sen University, China (No. 2020/72).

\section{ACKNOWLEDGMENTS}

We would like to thank Bradley Otterson, NIH Library Editing Service, for reviewing the manuscript.

3. Li SF, Zhao FR, Shao JJ, Xie YL, Chang HY, Zhang YG. Interferon-omega: current status in clinical applications. Int Immunopharmacol. (2017) 52:25360. doi: 10.1016/j.intimp.2017.08.028

4. Prokunina-Olsson L, Muchmore B, Tang W, Pfeiffer RM, Park H, Dickensheets H, et al. A variant upstream of IFNL3 (IL28B) creating a new interferon gene IFNL4 is associated with impaired clearance of hepatitis C virus. Nat Genet. (2013) 45:164-71. doi: 10.1038/ng.2521

5. Crotta S, Davidson S, Mahlakoiv T, Desmet CJ, Buckwalter MR, Albert ML, et al. Type I and type III interferons drive redundant amplification loops to 
induce a transcriptional signature in influenza-infected airway epithelia. PLoS Pathog. (2013) 9:e1003773. doi: 10.1371/journal.ppat.1003773

6. Piehler J, Thomas C, Garcia KC, Schreiber G. Structural and dynamic determinants of type I interferon receptor assembly and their functional interpretation. Immunol Rev. (2012) 250:317-34. doi: 10.1111/imr.12001

7. Taniguchi $T$, Takaoka A. The interferon-alpha/beta system in antiviral responses: a multimodal machinery of gene regulation by the IRF family of transcription factors. Curr Opin Immunol. (2002) 14:111-6. doi: 10.1016/S0952-7915(01)00305-3

8. Beiting DP. Protozoan parasites and type I interferons: a cold case reopened. Trends Parasitol. (2014) 30:491-8. doi: 10.1016/j.pt.2014.07.007

9. Ginouvès $M$, Simon $S$, Bourreau $E$, Lacoste V, Ronet $C$, Couppié $P$, et al. Prevalence and distribution of Leishmania RNA virus 1 in Leishmania parasites from French Guiana. Am J Trop Med Hyg. (2016) 94:102-6. doi: 10.4269/ajtmh.15-0419

10. Adaui V, Lye LF, Akopyants NS, Zimic M, Llanos-Cuentas A, Garcia L, et al. Association of the endobiont double-stranded RNA virus LRV1 with treatment failure for human leishmaniasis caused by Leishmania braziliensis in Peru and Bolivia. J Infect Dis. (2016) 213:112-21. doi: 10.1093/infdis/jiv354

11. Rossi M, Castiglioni P, Hartley MA, Eren RO, Prevel F, Desponds C, et al. Type I interferons induced by endogenous or exogenous viral infections promote metastasis and relapse of leishmaniasis. Proc Natl Acad Sci USA. (2017) 114:4987-92. doi: 10.1073/pnas.1621447114

12. Rath CT, Schnellrath LC, Damaso CR, de Arruda LB, Vasconcelos P, Gomes C, et al. Amazonian Phlebovirus (Bunyaviridae) potentiates the infection of Leishmania (Leishmania) amazonensis: role of the PKR/IFN1/IL-10 axis. PLoS Negl Trop Dis. (2019) 13:e7500. doi: 10.1371/journal.pntd.0007500

13. Uchida L, Espada-Murao LA, Takamatsu Y, Okamoto K, Hayasaka D, Yu F, et al. The dengue virus conceals double-stranded RNA in the intracellular membrane to escape from an interferon response. Sci Rep. (2014) 4:7395. doi: 10.1038/srep07395

14. Medina FA, Torres-Malavé G, Chase AJ, Santiago GA, Medina JF, Santiago $\mathrm{LM}$, et al. Differences in type I interferon signaling antagonism by dengue viruses in human and non-human primate cell lines. PLoS Negl Trop Dis. (2015) 9:e3468. doi: 10.1371/journal.pntd.0003468

15. World Health Organization. World Malaria Report. Geneva. (2019). p. 15.

16. D'Acremont V, Kilowoko M, Kyungu E, Philipina S, Sangu W, Kahama-Maro J, et al. Beyond malaria-causes of fever in outpatient Tanzanian children. $N$ Engl J Med. (2014) 370:809-17. doi: 10.1056/NEJMoa1214482

17. Edwards CL, Zhang V, Werder RB, Best SE, Sebina I, James KR, et al. Coinfection with blood-stage Plasmodium promotes systemic type I interferon production during pneumovirus infection but impairs inflammation and viral control in the lung. Clin Vaccine Immunol. (2015) 22:477-83. doi: 10.1128/CVI.00051-15

18. Hassan A, Wlodarczyk MF, Benamar M, Bassot E, Salvioni A, Kassem S, et al. A virus hosted in malaria-infected blood protects against $\mathrm{T}$ cell-mediated inflammatory diseases by impairing DC function in a type I IFN-dependent manner. mBio. (2020) 11:e03394-19. doi: 10.1128/mBio.03394-19

19. Dubey JP. Toxoplasmosis of Animals and Humans. Boca Raton: CRC Press (2009).

20. Lepelley A, Louis S, Sourisseau M, Law HK, Pothlichet J, Schilte C, et al. Innate sensing of HIV-infected cells. PLoS Pathog. (2011) 7:e1001284. doi: 10.1371/journal.ppat.1001284

21. Peng WM, Yu CF, Allam JP, Oldenburg J, Bieber T, Hoch J, et al. Inhibitory oligodeoxynucleotides downregulate herpes simplex virusinduced plasmacytoid dendritic cell type I interferon production and modulate cell function. Hum Immunol. (2007) 68:879-87. doi: 10.1016/j.humimm.2007.10.008

22. Honda K, Yanai H, Negishi H, Asagiri M, Sato M, Mizutani T, et al. IRF-7 is the master regulator of type-I interferon-dependent immune responses. Nature. (2005) 434:772-7. doi: 10.1038/nature03464

23. Pierog PL, Zhao Y, Singh S, Dai J, Yap GS, Fitzgerald-Bocarsly P. Toxoplasma gondii inactivates human plasmacytoid dendritic cells by functional mimicry of IL-10. J Immunol. (2018) 200:186-95. doi: 10.4049/jimmunol.1701045

24. Osborne LC, Monticelli LA, Nice TJ, Sutherland TE, Siracusa MC, Hepworth MR, et al. Coinfection. Virus-helminth coinfection reveals a microbiota-independent mechanism of immunomodulation. Science. (2014) 345:578-82. doi: 10.1126/science.125 6942

25. McFarlane AJ, McSorley HJ, Davidson DJ, Fitch PM, Errington C, Mackenzie $\mathrm{KJ}$, et al. Enteric helminth-induced type I interferon signaling protects against pulmonary virus infection through interaction with the microbiota. J Allergy Clin Immunol. (2017) 140:1068-78. doi: 10.1016/j.jaci.2017.01.016

26. Behera AK, Kumar M, Lockey RF, Mohapatra SS. $2^{\prime}-5^{\prime}$ Oligoadenylate synthetase plays a critical role in interferon-gamma inhibition of respiratory syncytial virus infection of human epithelial cells. J Biol Chem. (2002) 277:25601-8. doi: 10.1074/jbc.M200211200

27. Jumat MR, Huong TN, Ravi LI, Stanford R, Tan BH, Sugrue RJ. Viperin protein expression inhibits the late stage of respiratory syncytial virus morphogenesis. Antiviral Res. (2015) 114:11-20. doi: 10.1016/j.antiviral.2014.11.007

28. Edwards MJ, Buchatska O, Ashton M, Montoya M, Bickle QD, Borrow P. Reciprocal immunomodulation in a schistosome and hepatotropic virus coinfection model. J Immunol. (2005) 175:6275-85. doi: 10.4049/jimmunol.175.10.6275

29. Kamal S, Madwar M, Bianchi L, Tawil AE, Fawzy R, Peters T, et al. Clinical, virological and histopathological features: long-term follow-up in patients with chronic hepatitis C co-infected with S. mansoni. Liver. (2000) 20:281-9. doi: 10.1034/j.1600-0676.2000.020004281.x

30. Kamal SM, Graham CS, He Q, Bianchi L, Tawil AA, Rasenack JW, et al. Kinetics of intrahepatic hepatitis C virus (HCV)-specific $\mathrm{CD}^{+} \mathrm{T}$ cell responses in HCV and Schistosoma mansoni coinfection: relation to progression of liver fibrosis. J Infect Dis. (2004) 189:1140-50. doi: $10.1086 / 382278$

31. Draz HM, Mahmoud SS, Ashour E, Shaker YM, Wu CH, Wu GY. Effects of PEG-interferon-alpha-2A on Schistosoma mansoni infection in mice. $J$ Parasitol. (2010) 96:703-8. doi: 10.1645/GE-2369.1

32. Abdel-Rahman M, El-Sayed M, El RM, Elsharkawy A, El-Akel W, Ghoneim $\mathrm{H}$, et al. Coinfection with hepatitis $\mathrm{C}$ virus and schistosomiasis: fibrosis and treatment response. World J Gastroenterol. (2013) 19:2691-6. doi: 10.3748/wjg.v19.i17.2691

33. Van Immerseel F, De Buck J, Pasmans F, Huyghebaert G, Haesebrouck F, Ducatelle R. Clostridium perfringens in poultry: an emerging threat for animal and public health. Avian Pathol. (2004) 33:537-49. doi: 10.1080/03079450400013162

34. Williams RB, Marshall RN, La Ragione RM, Catchpole J. A new method for the experimental production of necrotic enteritis and its use for studies on the relationships between necrotic enteritis, coccidiosis and anticoccidial vaccination of chickens. Parasitol Res. (2003) 90:19-26. doi: 10.1007/s00436-002-0803-4

35. Park SS, Lillehoj HS, Allen PC, Park DW, FitzCoy S, Bautista DA, et al. Immunopathology and cytokine responses in broiler chickens coinfected with Eimeria maxima and Clostridium perfringens with the use of an animal model of necrotic enteritis. Avian Dis. (2008) 52:14-22. doi: 10.1637/7997-041707-Reg

36. Davenport GC, Hittner JB, Otieno V, Karim Z, Mukundan H, Fenimore $\mathrm{PW}$, et al. Reduced parasite burden in children with falciparum malaria and bacteremia coinfections: role of mediators of inflammation. Mediators Inflamm. (2016) 2016:4286576. doi: 10.1155/2016/42 86576

37. Were T, Davenport GC, Hittner JB, Ouma C, Vulule JM, Ong'Echa JM, et al. Bacteremia in Kenyan children presenting with malaria. J Clin Microbiol. (2011) 49:671-6. doi: 10.1128/JCM.01864-10

38. Giacomini E, Iona E, Ferroni L, Miettinen M, Fattorini L, Orefici $\mathrm{G}$, et al. Infection of human macrophages and dendritic cells with Mycobacterium tuberculosis induces a differential cytokine gene expression that modulates $\mathrm{T}$ cell response. J Immunol. (2001) 166:7033-41. doi: 10.4049/jimmunol.166.12.7033

39. Flynn JL, Chan J. Immunology of tuberculosis. Annu Rev Immunol. (2001) 19:93-129. doi: 10.1146/annurev.immunol.19.1.93

40. Talaat KR, Bonawitz RE, Domenech P, Nutman TB. Preexposure to live Brugia malayi microfilariae alters the innate response of human dendritic cells to Mycobacterium tuberculosis. J Infect Dis. (2006) 193:196-204. doi: $10.1086 / 498912$ 
41. Giosue S, Casarini M, Alemanno L, Galluccio G, Mattia P, Pedicelli $G$, et al. Effects of aerosolized interferon-alpha in patients with pulmonary tuberculosis. Am J Respir Crit Care Med. (1998) 158:1156-62. doi: 10.1164/ajrccm.158.4.9803065

42. Reid AJ, Vermont SJ, Cotton JA, Harris D, Hill-Cawthorne GA, KonenWaisman S, et al. Comparative genomics of the apicomplexan parasites Toxoplasma gondii and Neospora caninum: coccidia differing in host range and transmission strategy. PLoS Pathog. (2012) 8:e1002567. doi: 10.1371/journal.ppat.1002567

43. Beiting DP, Peixoto L, Akopyants NS, Beverley SM, Wherry EJ, Christian DA, et al. Differential induction of TLR3-dependent innate immune signaling by closely related parasite species. PLOS ONE. (2014) 9:e88398. doi: 10.1371/journal.pone.0088398

44. Coomes SM, Pelly VS, Kannan Y, Okoye IS, Czieso S, Entwistle LJ, et al. IFNgamma and IL-12 restrict Th2 responses during helminth/Plasmodium co-infection and promote IFNgamma from Th2 cells. PLoS Pathog. (2015) 11:e1004994. doi: 10.1371/journal.ppat.1004994

45. Hegazy AN, Peine M, Helmstetter C, Panse I, Frohlich A, Bergthaler A, et al. Interferons direct Th2 cell reprogramming to generate a stable GATA$3^{+}$Tbet $^{+}$cell subset with combined Th2 and Th1 cell functions. Immunity. (2010) 32:116-28. doi: 10.1016/j.immuni.2009.12.004

46. Coban C, Ishii KJ, Kawai T, Hemmi H, Sato S, Uematsu S, et al. Tolllike receptor 9 mediates innate immune activation by the malaria pigment hemozoin. J Exp Med. (2005) 201:19-25. doi: 10.1084/jem.20041836

47. Davidson S, Kaiko G, Loh Z, Lalwani A, Zhang V, Spann K, et al. Plasmacytoid dendritic cells promote host defense against acute pneumovirus infection via the TLR7-MyD88-dependent signaling pathway. J Immunol. (2011) 186:593848. doi: 10.4049/jimmunol.1002635

48. Sharma S, DeOliveira RB, Kalantari P, Parroche P, Goutagny N, Jiang Z, et al. Innate immune recognition of an AT-rich stem-loop DNA motif in the Plasmodium falciparum genome. Immunity. (2011) 35:194-207. doi: 10.1016/j.immuni.2011.05.016

49. Ammann CG, Messer RJ, Peterson KE, Hasenkrug KJ. Lactate dehydrogenase-elevating virus induces systemic lymphocyte activation via TLR7-dependent IFNalpha responses by plasmacytoid dendritic cells. PLoS ONE. (2009) 4:e6105. doi: 10.1371/journal.pone.00 06105

50. Eren RO, Reverte M, Rossi M, Hartley MA, Castiglioni P, Prevel F, et al. Mammalian innate immune response to a Leishmania-resident RNA virus increases macrophage survival to promote parasite persistence. Cell Host Microbe. (2016) 20:318-28. doi: 10.1016/j.chom.2016. 08.001

51. Ives A, Ronet C, Prevel F, Ruzzante G, Fuertes-Marraco S, Schutz F, et al. Leishmania RNA virus controls the severity of mucocutaneous leishmaniasis. Science. (2011) 331:775-8. doi: 10.1126/science.11 99326

52. Goritzka M, Makris S, Kausar F, Durant LR, Pereira C, Kumagai Y, et al. Alveolar macrophage-derived type I interferons orchestrate innate immunity to RSV through recruitment of antiviral monocytes. J Exp Med. (2015) 212:699-714. doi: 10.1084/jem.20140825

53. Taniguchi $\mathrm{T}$, Takaoka A. A weak signal for strong responses: interferon-alpha/beta revisited. Nat Rev Mol Cell Biol. (2001) 2:378-86. doi: $10.1038 / 35073080$
54. Aksoy E, Zouain CS, Vanhoutte F, Fontaine J, Pavelka N, Thieblemont $\mathrm{N}$, et al. Double-stranded RNAs from the helminth parasite Schistosoma activate TLR3 in dendritic cells. J Biol Chem. (2005) 280:277-83. doi: 10.1074/jbc.M411223200

55. Trottein F, Pavelka N, Vizzardelli C, Angeli V, Zouain CS, Pelizzola M, et al. A type I IFN-dependent pathway induced by Schistosoma mansoni eggs in mouse myeloid dendritic cells generates an inflammatory signature. $J$ Immunol. (2004) 172:3011-7. doi: 10.4049/jimmunol.172.5.3011

56. Parroche P, Lauw FN, Goutagny N, Latz E, Monks BG, Visintin A, et al. Malaria hemozoin is immunologically inert but radically enhances innate responses by presenting malaria DNA to Toll-like receptor 9. Proc Natl Acad Sci USA. (2007) 104:1919-24. doi: 10.1073/pnas.0608745104

57. Gowda NM, Wu X, Gowda DC. TLR9 and MyD88 are crucial for the development of protective immunity to malaria. J Immunol. (2012) 188:507385. doi: 10.4049/jimmunol.1102143

58. Yu X, Cai B, Wang M, Tan P, Ding X, Wu J, et al. Cross-regulation of two type I interferon signaling pathways in plasmacytoid dendritic cells controls anti-malaria immunity and host mortality. Immunity. (2016) 45:1093-107. doi: 10.1016/j.immuni.2016.10.001

59. Gallego-Marin C, Schrum JE, Andrade WA, Shaffer SA, Giraldo LF, Lasso AM, et al. Cyclic GMP-AMP synthase is the cytosolic sensor of Plasmodium falciparum genomic DNA and activates type I IFN in malaria. J Immunol. (2018) 200:768-74. doi: 10.4049/jimmunol.1701048

60. Kremsner PG, Winkler S, Wildling E, Prada J, Bienzle U, Graninger $\mathrm{W}$, et al. High plasma levels of nitrogen oxides are associated with severe disease and correlate with rapid parasitological and clinical cure in Plasmodium falciparum malaria. Trans R Soc Trop Med Hyg. (1996) 90:44-7. doi: 10.1016/S0035-9203(96)90476-9

61. Rothwell L, Young JR, Zoorob R, Whittaker CA, Hesketh P, Archer A, et al. Cloning and characterization of chicken IL-10 and its role in the immune response to Eimeria maxima. I Immunol. (2004) 173:2675-82. doi: 10.4049/jimmunol.173.4.2675

62. Steed AL, Christophi GP, Kaiko GE, Sun L, Goodwin VM, Jain U, et al. The microbial metabolite desaminotyrosine protects from influenza through type I interferon. Science. (2017) 357:498-502. doi: 10.1126/science.aam5336

63. Yarovinsky F, Zhang D, Andersen JF, Bannenberg GL, Serhan CN, Hayden MS, et al. TLR11 activation of dendritic cells by a protozoan profilin-like protein. Science. (2005) 308:1626-9. doi: 10.1126/science.1109893

64. Koblansky AA, Jankovic D, Oh H, Hieny S, Sungnak W, Mathur $\mathrm{R}$, et al. Recognition of profilin by Toll-like receptor 12 is critical for host resistance to Toxoplasma gondii. Immunity. (2013) 38:119-30. doi: 10.1016/j.immuni.2012.09.016

Conflict of Interest: The authors declare that the research was conducted in the absence of any commercial or financial relationships that could be construed as a potential conflict of interest.

Copyright (C) $2020 \mathrm{Ma}$, Su and Lu. This is an open-access article distributed under the terms of the Creative Commons Attribution License (CC BY). The use, distribution or reproduction in other forums is permitted, provided the original author(s) and the copyright owner(s) are credited and that the original publication in this journal is cited, in accordance with accepted academic practice. No use, distribution or reproduction is permitted which does not comply with these terms. 